\title{
Animal health counseling and animal husbandry management towards smart, creative and independent
}

\author{
Azhari $^{*}$, Surya Prayoga ${ }^{2}$, Rizki Hamdani Hasibuan ${ }^{2}$ \\ ${ }^{1}$ Department of Physics, Faculty of Mathematics and Natural Sciences, Universitas Sumatera \\ Utara, Medan, Indonesia \\ ${ }^{2}$ Faculty of Agriculture, Universitas Sumatera Utara, Medan, Indonesia \\ *Email: azhari@usu.ac.id
}

\begin{abstract}
Indonesia is famous for its natural diversity of flora and fauna. Opportunities are very wide open for young people, coupled with the declining interest of young people to wrestle in agriculture. With the existence of young people who are interested in the world of agriculture, it will create a tremendous impact on Indonesian agriculture, benefit the masses with a healthier and more advanced approach to using technology. In this regard, the dedication team conducts an introduction to the introduction of the world of early age livestock and health management counseling for livestock. Where farmers and ranchers here rarely get counseling and training, so many do not know about the potential of the village that can be used for their benefit without spending a large fee. The team has designed the materials needed according to the needs of farmers and ranchers so that in the future they will easily understand and apply them in their work later. This counseling was held 3 times a meeting which lasted several hours as needed. This counseling is carried out on an ongoing basis starting from the preparation of counseling, material preparation, implementation of counseling and report writing. The extension participants were aimed at farmer groups and ranchers.
\end{abstract}

Keyword: Animal husbandry, Animal health

\begin{abstract}
Abstrak
Alam Indonesia terkenal dengan keaneragaman flora dan faunanya.Peluang sangat terbuka lebar bagi para anak muda, ditambah lagi dengan semakin menurunnya minat anak muda untuk bergelut dibidang pertanian. Dengan adanya anak anak muda yang tertarik menggeluti dunia pertanian maka itu akan menciptakan dampak yang luar biasa bagi pertanian Indonesia, memberi manfaat kepada massa dengan pendekatan yang lebih sehat dan maju menggunakan teknologi. Sehubungan dengan hal ini, tim pengabdian melakukan penyuluhan pengenalan dunia ternak usia dini dan penyuluhan manajemen kesehatan untuk ternak. Dimana para petani dan peternak disini jarang mendapatkan penyuluhan dan pelatihan, sehingga banyak yang tidak mengetahui tentang potensi desa yang bisa dimanfaatkan untuk keuntungan mereka tanpa mengeluarkan biaya yang besar. Tim telah merancang materi yang dibutuhkan sesuai dengan kebutuhan untuk para petani maupun peternak sehingga untuk ke depannya mereka mudah memahami dan mengaplikasikannya dalam pekerjaan mereka nantinya. Penyuluhan ini dilakukan sebanyak 3 kali pertemuan yang berlangsung selama beberapa jam sesuai kebutuhan. Penyuluhan ini dilaksanakan secara berkesinambungan mulai dari persiapan penyuluhan, penyusunan materi, pelaksanaan penyuluhan dan penulisan laporan. Peserta penyuluhan ditujukan untuk kelompok tani dan peternak.
\end{abstract}

Kata Kunci: Peternakan, Kesehatan ternak

\section{PENDAHULUAN}

Masalah peternakan adalah masih minimnya pengetahuan masyarakat mengenai beternak yang baik. banyak masyarakat umumnya beternak secara turun temurun \{dilepas liarkan\} sehingga hasil ternak tidak banyak dihasilkan, masalah penyakit yang banyak, obat-obatan yang tidak tersedia di desa sei siarti, mantri peternakan yang tidak ada, alat peternakan seperti mesin pencacah 
yang harus diterapkan, bibit ternak seperti babi, kambing, dan sapi yang disini sudah rusak genetiknya dikarenakan perkawinan sedarah karena dilepas liarkan, masalah mengenai perusahaan yang tidak mengizinkan peternak untuk mengembalakan ternaknya sehingga pakan untuk ternak nantinya akan terancam, penyediaan bibit rumput yang harus di lakukan dan diberikan kepeternak.

Masalah selanjutnya yaitu Nelayan dimana masih kurangnya ilmu pengetahuan tentang membudidaya ikan, gelombang besar yang terjadi di sungai siarti, air yang masih bersifat asam yang tinggi, alat penangkap yang masih kurang memadai, bibit ikan yang tidak tersedia, penyakit ikan yang belum dapat diatasi, Lahan yang cukup luas harus dimanfaatkan sebaik mungkin, tak terkecuali lahan halaman rumah untuk menunjang perekonomian keluarga bahkan pemanfaatan hasil tanah juga harus dimanfaatkan sebaik mungkin.

Semua fasilitas yang baik yang ada di desa ini pasti tidak akan terlepas dari kekurangan. Pemberdayaan masyarakat yang diikuti oleh pendidikan dan pelatihan merupakan kunci untuk semua kemajuan dan perkembangan yang berkualitas. Proses pembelajaran hendaknya dapat mengembangkan kemampuan dan membentuk penduduk menjadi masyarakat yang berkualitas. Pendidikan yang berkualitas tentunya diharapkan kehadirannya di setiap wilayah di Indonesia

\section{METODE PELAKSANAAN}

Agar Masyarakat/peternak mendapatkan dan mengetahui kesehatan ternak nya, mencegah penyakit ternak serta cara pengobatannya secara tradisional dengan bahan yang bisa didapatkan di daerah tersebut. Untuk meningkatkan pengetahuan peternak terhadap manajemen peternakan seperti sistem pemberian pakan, pemilihan bibit yang baik, serta pengelolaan kandang pada ternak kambing,domba dan sapi. Mengadakan pengajaran dan praktek langsung kepada masyarakat/peternak/kelompok tani cara membuat pakan tambahan seperti garam jilat secara sederhana untuk meningkatkan gizi pada ternak. Kegiatan ini dilakukan agar kedepannya peternak dapat lebih mandiri dan inovasi dalam melakukan suatu kegiatan beternak. Timbulnya kesadaran masyarakat dalam memperbaiki manajemen peternakan agar output yang dihasilkan lebih baik

\section{HASIL DAN PEMBAHASAN}

Kegiatan Penyuluhan tentang bagaimana manajemen pertanian dan peternakan yang baik dan benar dengan memanfaatkan kearifan lokal dan potensi desa yang sudah ada. Masyarakat, petani, dan peternak dapat mengolah dan memanfaatkan sumber daya alam yang ada didesa untuk membuat kompos bagi tanaman mereka, pakan ternak dari limbah pertanian, membuat pakan tambahan untuk ternak, dapat mengetahui bibit yang bagus untuk output ternak maupun tanaman mereka, dapat mengetahui cara membuat obat tradisional untuk hewan ternak yang sakit. Petani dan peternak menjadi lebih aktif, inovasif serta mandiri dalam memanajemen pertanian dan peternakan, khususnya dalam mengolah dan memanfaatkan potensi desa.
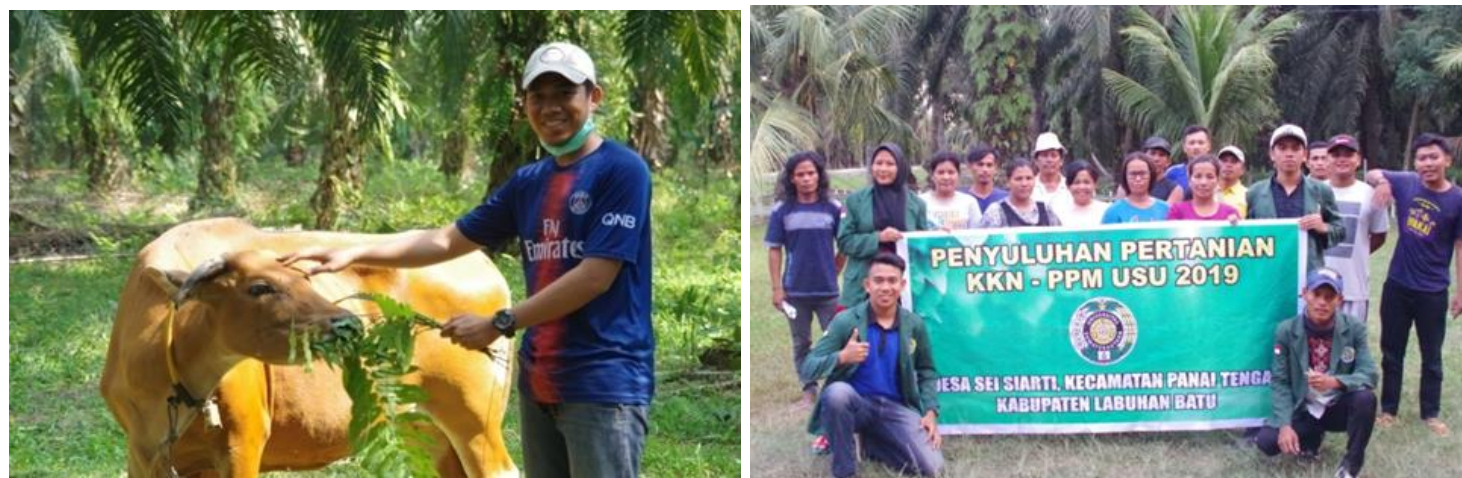

Gambar 3.1. Penyuluhan Kesehatan Ternak 


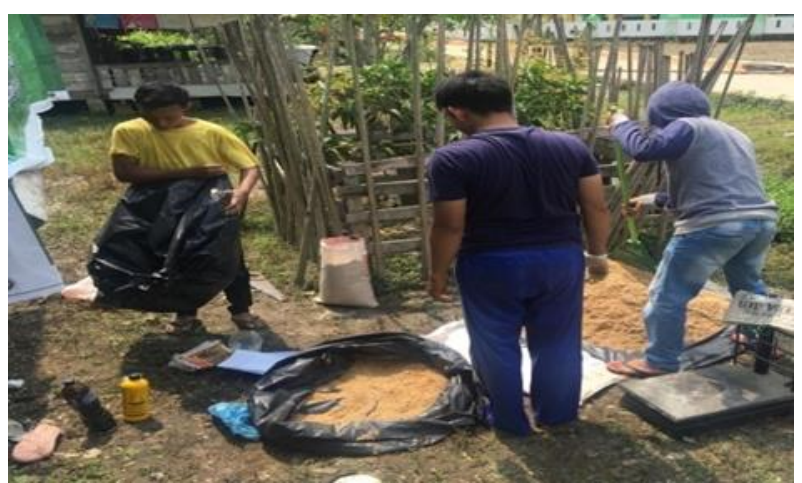

Gambar 3.2. Pembuatan Garam Jilat Ternak

\section{KESIMPULAN}

Sebelum kegiatan pengabdian, masih banyak masyarakat yang tidak mengetahui adanya potensi desa yang dapat diolah dan dimanfaatkan untuk keuntungan mereka. Hal ini dikarenakan oleh kurangnya pengetahuan tentang manajemen pertanian dan peternakan yang dimiliki oleh masyarakat desa sehingga perlu diadakan nya penyuluhan atau pelatihan untuk para petani dan peternak. Faktor lainnya adalah kurangnya sarana dan informasi yang didapat oleh para petani dan peternak. Karena ketidaktahuan tersebut banyak masyarakat yang mengeluh akan tidak bagus nya hasil tanaman atau ternak yang dirawatnya yang mengakibatkan pendapatan mereka tidak cukup.

Setelah program pengabdian dilaksanakan, terungkap bahwa banyak potensi desa yang masih belum diolah dan dimanfaatkan dengan baik, seperti limbah pertanian yang harusnya bisa dijadikan pakan untuk ternak. Dalam hal ini, petani dan peternak mengikuti penyuluhan ini dengan antusias. Mereka memiliki rasa ingin tahu yang tinggi untuk meningkatkan pengetahuan mereka tentang manajemen pertanian dan peternakan guna diterapkan dikebun maupun pada ternaknya. Berkat dukungan pemerintah setempat dan pihak kelompok tani dan peternak, program ini dapat dijalankan dengan baik tanpa halangan yang berarti. Kegiatan ini dapat dilaksanakan sesuai dengan yang telah direncanakan

\section{UCAPAN TERIMAKASIH}

Pada kesempatan ini kami mengucapkan terima kasih kepada Rektor Universitas Sumatera Utara, Ketua dan Sekretaris Lembaga Pengabdian Pada Masyarakat USU, Pegawai LPPM yang banyak membantu kegiatan pengabdian kepada masyarakat ini baik berupa moral maupun materiil sehingga memperlancar kegiatan kami.

\section{DAFTAR PUSTAKA}

Muriithi, K. M., Huka, S. G., Njati, C. I. 2014. Factors influencing growth of dairy farming business in amentia south district of mere county, Kenya. IOSR Journal of Business and Management 16(4): 21-31.

Nuryadi dan Wahjuningsih, S. 2011. Penampilan Reproduksi Sapi Peranakan Ongole dan Peranakan Limousin di Kabupaten Malang. J. Ternak Tropikal 12 (1): 76-81.

Pasandaran, E, A., Djajanegara, K., Kariyasa dan F. Kasryno. 2006. Kerangka Konseptual Integrasi Tanaman-Ternak di Indonesia. Dalam: Integrasi Tanaman-Ternak di Indonesia. Badan Penelitian dan Pengembangan Pertanian. Pp. 11-31. 
Rajendran, K., S. Aslanzadeh, and M. J. Taherzadeh. 2012. Household 2942.-biogas digesters-A review. Energies 5: 2911.

Sudono, A., R. F. Rosdiana, dan B. S. Setiawan. 2005. Beternak Sapi Perah Secara Intensif. Agromedia Pustaka. Jakarta

Umiyasih, U., Aryogi, Y. N. Anggraeny, M. Zulbardi, dan Kuswandi. 2003. Analisis respon perlakuan pakan terhadap keragaan produksi sapi potong dara. Prosiding Seminar Nasional Teknologi Peternakan dan Veteriner. Pusat Penelitian dan Pengembangan Peternakan. Bogor.

Widodo, T. W. dan A. Asari. 2011. Inovasi Mekanisasi Mendukung Penyediaan Energi Rumah Tangga Petani. Edisi 1-7 Juni no. 3408 Tahun XLI. Agronovasi. Sinartani 